\title{
Evaluation of hybrid steel fiber reinforcement in high performance geopolymer composites
}

\author{
X. Gao $\cdot$ Q. L. Yu • R. Yu • H. J. H. Brouwers
}

Received: 29 June 2016/ Accepted: 30 March 2017/Published online: 10 April 2017

(C) The Author(s) 2017. This article is an open access publication

\begin{abstract}
In this paper, cement free high performance alkali activated slag-fly ash composites are designed by applying the modified Andreasen and Andersen particle packing model, and steel fibers of two lengths are applied for strength reinforcement and shrinkage compensation. The influence of the fiber length, dosage and hybrid on the fresh behavior, compressive strength, stress-stain behavior under flexural load, porosity and drying shrinkage are evaluated, and the gel structure of this blended alkali system is also identified. The results show that by applying the hybrid fiber together with the particle packing design approach, a compressive strength of around $100 \mathrm{MPa}$ can be achieved with a $w / p$ ratio of 0.4. The addition of steel fiber slightly decreases the slump flow and increases the porosity, but effectively inhibits the drying shrinkage and improves the stressstain behavior. The hybrid usage of long and short fiber shows a synergetic effect and leads to the
\end{abstract}

X. Gao · Q. L. Yu (ه) · R. Yu · H. J. H. Brouwers

Department of the Built Environment, Eindhoven

University of Technology, P.O. Box 513,

5600 MB Eindhoven, The Netherlands

e-mail: q.yu@bwk.tue.nl

X. Gao $\cdot$ R. Yu $\cdot$ H. J. H. Brouwers

State Key Laboratory of Silicate Materials for Architectures, Wuhan University of Technology, 430070 Wuhan, People's Republic of China optimum strength. The steel fiber reinforcement is beneficial for the application of alkali activated materials.

Keywords Slag-fly ash blends · Hybrid steel fiber . Mechanical properties · Drying shrinkage · Porosity · Stress-strain behavior

\section{Introduction}

The production of Portland cement is usually accompanied with high carbon emissions and energy costs. In order to reduce the negative environmental impacts, the utilization of alkali activated materials (AAMs) as a substitute has been extensively studied in recent years. This type of material usually exhibits excellent performances such as mechanical properties [1], durability [2, 3], thermal properties [4] together with low environmental impacts [5] compared to Portland cement. Based on the reaction mechanisms of the starting materials, two types of binding systems can be classified. One is the $(\mathrm{Si}+\mathrm{Ca})$ system, having a C-A$\mathrm{S}-\mathrm{H}$ type gel with a low $\mathrm{Ca} / \mathrm{Si}$ ratio and a high $\mathrm{Al}$ incorporation as the main reaction product [6]. The other is the $(\mathrm{Si}+\mathrm{Al})$ system, the major reaction product is an N-A-S-H type gel within three-dimensional networks [7]. Both systems exhibit distinct behaviors due to their differences in reaction mechanism and gel characteristics. 
The recent investigations that focus on the blended alkaline systems bring a promising future for the application of alkali activated materials, because of the better balance between mechanical properties and durability when mixing calcium enriched precursors with aluminosilicates [8-11]. The main reaction products in the blended system are stably coexisting C-(A)-S-H and N-A-S-H type gels [12-14]. Besides, the influences of key synthesizing factors on reaction kinetics, gel characteristics, mechanical properties and durability were intensively investigated [15-21]. The recent understandings on the blended alkali systems provide solid theoretical support for the further researches. Several applications have already applied in practice such as high residential buildings, pre-cast structural components, floor slabs, wall panels and railway sleepers [22-24].

However, even though excellent performances can be achieved by the blended alkaline systems, the relatively high drying shrinkage because of the nature of both raw materials and activators is still a remaining issue that limits their large scale applications, since it is well linked to the cracking tendency and consequently the durability related properties. On the other hand, the application of steel fiber in Portland cement systems has proven its advantages in improving the flexural strength, fracture toughness, impact and fatigue resistance $[25,26]$, as well as the efficiency of reducing the shrinkage behavior of the brittle matrix $[27,28]$. The randomly dispersed fibers within the matrix reduce the extension and growth of microcracks by providing a stress transfer capacity, by which the generated inner stress can be transferred into other stable areas of the matrix [29-31]. Additionally, it should be noted that steel fibers with different lengths play distinct roles in inhibiting the cracks, namely short fibers are mainly for bridging the microcracks while long fibers are more efficient in reducing the macro-cracks $[32,33]$. Those improved properties may also indicate the potential of using steel fiber in alkali activated systems. Bernal et al. [27] applied steel fiber with dosages of 40 and $120 \mathrm{~kg} / \mathrm{m}^{3}$ in waterglass activated slag, the results showed that the flexural strength was largely improved and there was a reduction in compressive strength when increasing the fiber content; also water absorption and permeable porosity were reduced. Aydin et al. [31] used long and short steel fibers with the volume fraction up to $2 \%$ in waterglass activated slag-silica fume blends, and they reported that as the fiber content increases, there is a reduction on workability and drying shrinkage; while mixes with a higher fiber content and longer length exhibit higher compressive and flexural strength. Improvements in mechanical properties because of the steel fiber addition were also reported in $[34,35]$. However, there presents limited mechanism study and performance evaluation regarding the effect of hybrid steel fiber on the blended alkaline system.

The objective of this study is to design cement free high performance alkali activated slag-fly ash composites; steel fibers of two different lengths are applied for strength reinforcement and shrinkage inhibiting. All mortar mixtures are designed by applying the modified Andreasen and Andersen particle packing model, in order to achieve an optimal packing of the granular ingredients and therefore a condensed matrix. The influences of fiber length and dosage, as well as the utilization of hybrid fibers on workability, compressive strength, flexural strength, porosity and drying shrinkage are investigated. Additionally, the reaction products of this blended alkali binder are identified by using thermo-gravimetry (TG) and Fourier transform infrared spectroscopy (FTIR).

\section{Experiment}

\subsection{Materials}

The solid precursors used in this study were commercial ground granulated blast furnace slag and Class $\mathrm{F}$ fly ash. Their major chemical compositions were analyzed by X-ray fluorescence and are shown in Table 1. Limestone powder was used as a filler. Two

Table 1 Major chemical composition of fly ash and slag

\begin{tabular}{lcl}
\hline Oxides $(w t \%)$ & FA & GGBS \\
\hline $\mathrm{SiO}_{2}$ & 54.62 & 30.23 \\
$\mathrm{Al}_{2} \mathrm{O}_{3}$ & 24.42 & 12.58 \\
$\mathrm{CaO}$ & 4.44 & 40.51 \\
$\mathrm{MgO}$ & 1.43 & 9.05 \\
$\mathrm{Fe}_{2} \mathrm{O}_{3}$ & 7.21 & 0.60 \\
$\mathrm{Na}_{2} \mathrm{O}$ & 0.73 & - \\
$\mathrm{K}_{2} \mathrm{O}$ & 1.75 & 0.43 \\
$\mathrm{SO}_{3}$ & 0.46 & 3.47 \\
$\mathrm{LOI}$ & 2.80 & 1.94 \\
\hline
\end{tabular}


types of sand were used as fine aggregates: a micro sand $(0-1 \mathrm{~mm}$, provided by Graniet-Import Benelux B.V., the Netherlands) and a normal sand with the fractions of 0-2 mm. Besides, two types of straight steel fibers were applied: (1) fiber length of $13 \mathrm{~mm}$ with diameter of $0.2 \mathrm{~mm}$; (2) fiber length of $6 \mathrm{~mm}$ with diameter of $0.16 \mathrm{~mm}$. The specific densities of the raw materials and steel fibers are presented in Table 2 while the detailed particle size distributions of the solid particles are given in Fig. 1. For the alkaline activators, a mixture of sodium hydroxide (analytical level of $99 \mathrm{wt} \%)$ and a commercial sodium silicate solution $\left(27.69 \% \mathrm{SiO}_{2}, 8.39 \% \mathrm{Na}_{2} \mathrm{O}\right.$ and $63.92 \% \mathrm{H}_{2} \mathrm{O}$ by mass) was used. The desired activator modulus (Ms, $\mathrm{SiO}_{2} / \mathrm{Na}_{2} \mathrm{O}$ molar ratio) was achieved by adding the appropriate amount of sodium hydroxide into the sodium silicate solution. Distilled water was added in order to reach the desired water/binder ratio. The

Table 2 Specific densities of the solid materials

\begin{tabular}{ll}
\hline Solid materials & Specific density $\left(\mathrm{kg} / \mathrm{m}^{3}\right)$ \\
\hline Slag & 2930 \\
Fly ash & 2300 \\
Limestone powder & 2710 \\
Micro sand & 2720 \\
Normal sand & 2640 \\
Short steel fiber & 7800 \\
Long steel fiber & 7800 \\
\hline
\end{tabular}

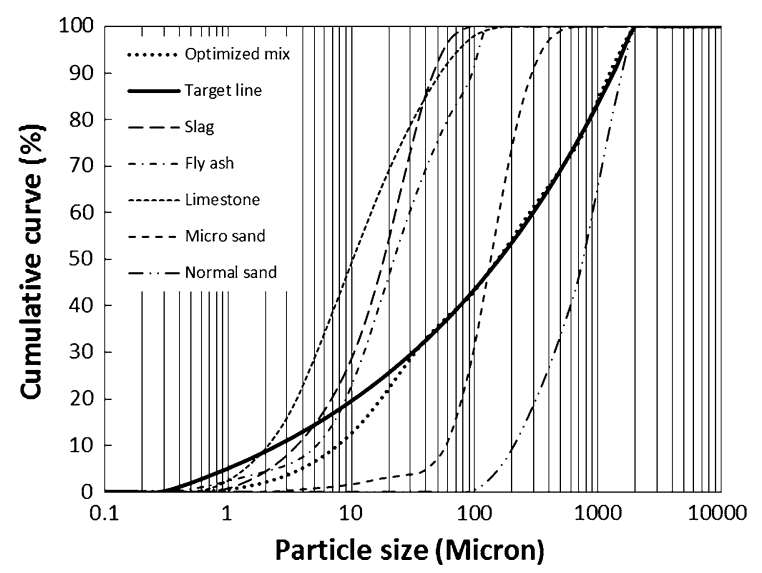

Fig. 1 Particle size distributions of the raw materials, the target curve and the resulting integral grading line of the mixture mixed activator solution was cooled down to room temperature for $24 \mathrm{~h}$ before further use.

\subsection{Mix design methodology}

The mixes of the alkali activated composites were designed following a mathematical model in order to achieve the optimized packing of the granular solid materials [36]. Theoretically, a minimal porosity can be achieved by an optimal particle size distribution of all solid materials, as shown in Eq. (1):

$P(D)=\left(\frac{D}{D_{\max }}\right)^{q}$

Based on this packing theory, a new model, so called the modified Andreasen and Andersen (A\&A) model, was proposed by taking into account of the minimal particle size, as shown in Eq. (2) [37]. In the present study, it is applied as a target function for the subsequent granular optimization of the individual solid materials.

$P(D)=\frac{D^{q}-D_{\min }^{q}}{D_{\max }^{q}-D_{\min }^{q}}$

where $P(D)$ is a fraction of the total solids materials that are smaller than the particle size $D(\mu \mathrm{m}), D_{\max }$ is the maximum particle size $(\mu \mathrm{m}), D_{\min }$ is the minimum particle size $(\mu \mathrm{m})$ and $q$ is the distribution modulus. The distribution modulus $(q)$ in the model is fixed at 0.23 based on the previous experiences [38, 39, 40, 41, 42, 43]. By using an optimization algorithm based on the Least Squares Method (LSM), as presented in Eq. (3), the proportions of each individual material in the mix are adjusted until an optimum fit between the composed mix grading curve and the target curve is reached $[42,43]$, namely minimized sum of the squares of the residuals (RSS) at defined particle sizes.

$\mathrm{RSS}=\sum_{i=1}^{n}\left(P_{\text {mix }}\left(D_{i}^{i+1}\right)-P_{\operatorname{tar}}\left(D_{i}^{i+1}\right)\right)^{2}$

where $P_{\text {mix }}$ is the composed mix, and the $P_{\text {tar }}$ is the target grading calculated from Eq. (2). Then the optimized mixture will possess a compact matrix due to the optimal packing. The particle size distributions of the raw materials, the target curve and the resulting integral grading curve of the mixture is shown in Fig. 1. Additionally, the fiber contents up to $1 \%$ by volume are added in the original system; its effect on 
the packing is not considered in this case but will be investigated in the future study. It should be noticed that applying the packing model not only benefits in achieving a dense matrix and the resulting improved properties, but also limits the presence of water between solids, and therefore leads to a relatively low total water demand, this is beneficial especially in alkali activated system, where no effective superplasticizers are available [34].

\subsection{Sample preparation}

The activator used in this study has an equivalent sodium oxide $\left(\mathrm{Na}_{2} \mathrm{O}\right)$ content of $5 \%$ by mass of the powder and an activator modulus of 1.4. The water/ powder ratio was kept constant as 0.4 in all mixtures. A slag/fly ash ratio of $80 / 20$ by mass is used in all mixtures. The mix proportions of the used materials are listed in Table 3. Steel fiber contents up to $1 \%$ (by volume of the mortar) with an interval of $0.25 \%$ are applied. Samples with only long fiber or short fiber are prepared as references, and mixes with long/short fiber ratios of 80/20,60/40, 40/60 and 20/80 are studied. All mortar specimens were prepared in a laboratory mixer; firstly the solid precursors were added into the mixer followed by the fine fillers and aggregates, and finally the fibers. The casted samples are covered with a plastic film for the first $24 \mathrm{~h}$; then cured at a temperature of $20^{\circ} \mathrm{C}$ and a relative humidity of $95 \%$ until their testing age.

\subsection{Testing methods}

The workability of mortar samples was tested by the mini spread-flow test according to EN 1015-3 [44]. The compressive strength testing was carried out according to EN 196-1 [45]. Cubes samples were tested at the ages of 7 and 28 days. Each result is an average of three measurements. The flexural strength was tested using a Zwick Z020 instrument, under three-point loading using displacement control; the specimen sizes are $160 \times 40 \times 40 \mathrm{~mm}^{3}$, and a mid-span deflection rate is $0.10 \mathrm{~mm} / \mathrm{min}$ with a span of $100 \mathrm{~mm}$. The pre-load was performed with a force of $5 \mathrm{~N}$ and a speed of $10 \mathrm{~mm} /$ min. The used testing speed was $50 \mathrm{~N} / \mathrm{s}$ with a controlled force, the accuracy of the applied sensor is $0.1 \mathrm{~N}$. The data was collected with a time interval of $0.1 \mathrm{~s}$ and travel interval of $1 \mu \mathrm{m}$. The experiments were carried out to three samples per recipe. The displacement is measured by a displacement transducer. A setup graph of the flexural strength testing is shown in Fig. 2. Fourier transform infrared spectroscopy (FTIR) measurements were performed in a Varian 3100 instrument with the wavenumbers ranging from 4000 to $600 \mathrm{~cm}^{-1}$. The thermo-gravimetric (TG) analyses were conducted by using a STA $449 \mathrm{~F} 1$ instrument, samples were heated up to $1000{ }^{\circ} \mathrm{C}$ at a rate of $5{ }^{\circ} \mathrm{C} / \mathrm{min}$. Both FTIR and TG analyses were carried out at the age of 1,7 and $28 \mathrm{~d}$, respectively. The porosity was measured by applying the vacuum-saturation technique following the description given in NT Build 492 [46]. The water permeable porosity is calculated as:

Table 3 Mix proportion of alkali-activated slag-fly ash composites with steel fibers $\left(\mathrm{kg} / \mathrm{m}^{3}\right)$

\begin{tabular}{llllllllc}
\hline Mix & Activator & Slag & Fly ash & Limestone & Sand 0-1 & Sand 0-2 & Short fiber & Long fiber \\
\hline Ref & 379.8 & 461.9 & 115.5 & 144.3 & 270.6 & 811.9 & 0 & 0 \\
LF-0.25 & 378.9 & 460.7 & 115.2 & 143.9 & 269.9 & 809.9 & 0 & 19.5 \\
LF-0.50 & 377.9 & 459.6 & 114.9 & 143.6 & 269.2 & 807.8 & 0 & 39 \\
LF-0.75 & 377.0 & 458.4 & 114.6 & 143.2 & 268.6 & 805.8 & 0 & 58.5 \\
LF-1.00 & 376.0 & 457.3 & 114.3 & 142.9 & 268.0 & 803.8 & 0 & 78 \\
SF-0.25 & 378.9 & 460.7 & 115.2 & 143.9 & 269.9 & 809.9 & 19.5 & 0 \\
SF-0.50 & 377.9 & 459.6 & 114.9 & 143.6 & 269.2 & 807.8 & 39 & 0 \\
SF-0.75 & 377.0 & 458.4 & 114.6 & 143.2 & 268.6 & 805.8 & 58.5 & 0 \\
SF-1.00 & 376.0 & 457.3 & 114.3 & 142.9 & 268.0 & 803.8 & 78 & 0 \\
L/S-8/2 & 376.0 & 457.3 & 114.3 & 142.9 & 268.0 & 803.8 & 62.4 & 15.6 \\
L/S-6/4 & 376.0 & 457.3 & 114.3 & 142.9 & 268.0 & 803.8 & 46.8 & 31.2 \\
L/S-4/6 & 376.0 & 457.3 & 114.3 & 142.9 & 268.0 & 803.8 & 31.2 & 46.8 \\
L/S-2/8 & 376.0 & 457.3 & 114.3 & 142.9 & 268.0 & 803.8 & 15.6 & 62.4 \\
\hline
\end{tabular}




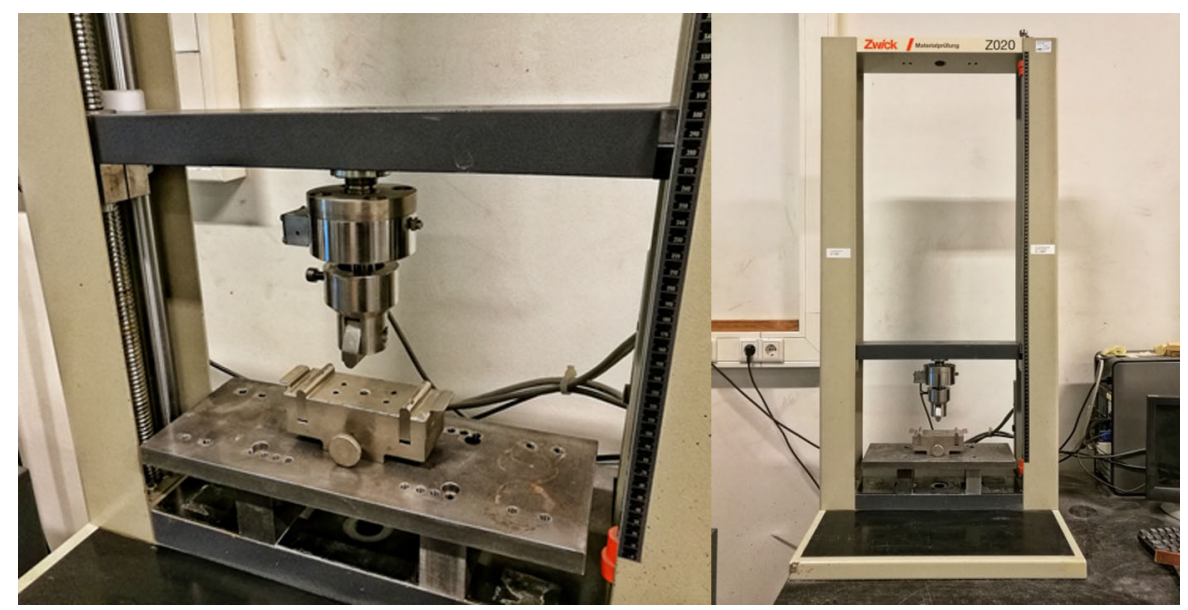

Fig. 2 Setup of the stress-strain behavior test

$P(\%)=\frac{M_{\mathrm{s}}-M_{\mathrm{d}}}{M_{\mathrm{s}}-M_{\mathrm{w}}} \times 100 \%$

where $P(\%)$ is the water permeable porosity, $M_{\mathrm{s}}$ (g) refers to the mass of the saturated sample in surface-dry condition in air, $M_{\mathrm{w}}(\mathrm{g})$ is the mass of water-saturated sample in water and $M_{\mathrm{d}}(\mathrm{g})$ is the mass of oven dried sample. The drying shrinkage tests were carried out using molds with dimensions of $40 \times 40 \times 160 \mathrm{~mm}^{3}$ under conditions of $20^{\circ} \mathrm{C}$ and relative humidity of $50 \%$, the initial length $\left(L_{0}\right)$ was measured at $24 \mathrm{~h}$ after casting, then the length $\left(L_{n}\right)$ was measured once per working day until the age of 28 days. Each result of the strength test is the average value of three tests, the results of fresh behavior, and porosity and drying shrinkage are an average of two tests. Figure 3 presents the curing container and the dial gauge that are used for shrinkage measuring. The curing box is sealed with an internal sensor control in order to achieve a constant relative humility and temperature.

\section{Results and discussion}

\subsection{Flowability}

The slump flows of the fresh alkali activated slag-fly ash mortars with long and short fiber additions are depicted in Fig. 4. It is clear that as the steel fiber content increases, the slump flow exhibits a gradual decrease in general, and the long steel fiber shows a more significant effect on the slump flow than the short ones. For samples without fiber addition, the slump flow is $25.9 \mathrm{~cm}$; and it slightly decreases to $23.1 \mathrm{~cm}$ when the short fiber content increases to $1 \mathrm{wt} . \%$. Similar trends are also shown in mixes containing long steel fibers. As the fiber content increases from 0 to $1 \%$, the slump flow gradually decreases from 25.9 to $20.6 \mathrm{~cm}$, which shows a higher decrement compared to the short fiber. This result is in line with the previous researches that the steel fiber addition presents a negative effect on flowability in both Portland cement system and alkali activated system [34, 47]. It is widely accepted that the effects of steel fibers on workability can be summarized as: the elongated shaped steel fiber with a relatively high surface area increases the cohesive forces between the fibers and the matrix; stiff fibers push apart the particles that larger than the fiber length and change the structure of the granular skeleton to some extent; the deformed steel fiber improves the anchorage between the fiber and matrix [32, 33]. Considering that only straight fibers with different lengths are used in this study, the decrease of slump flow here is due to the increased surface area and the resulting higher cohesive forces within the matrix. And long steel fibers have a relatively significant influence on this cohesive force. Because of the fact that the long fiber presents a relatively smaller surface area (compared to short fiber, with the same volume) but a more significant effect on flowability in this case, it seems that the internal cohesive forces play a more important role than surface area on the workability. The slump flows of samples with $1 \%$ fiber content and different long/ short fiber ratios $(80 / 20,60 / 40,40 / 60$ and 20/80) are 


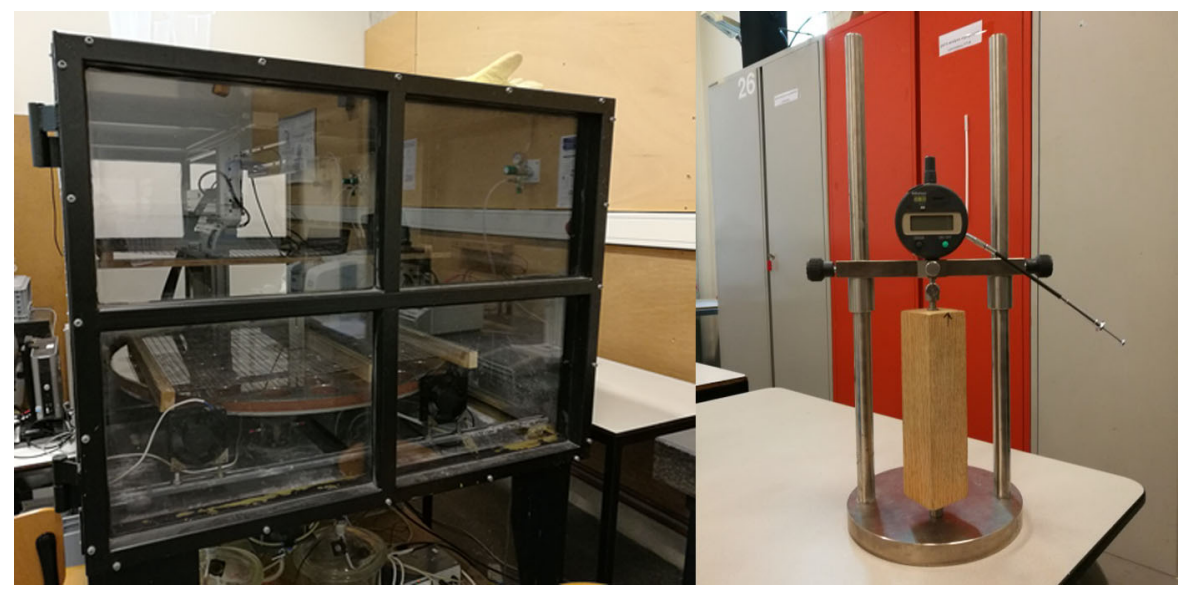

Fig. 3 Setup of the drying shrinkage test: constant humility curing and measuring

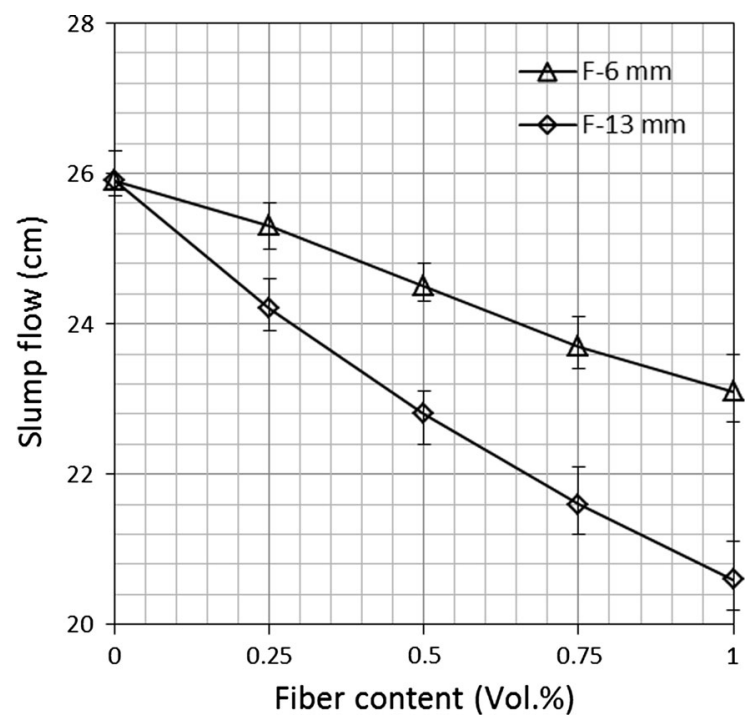

Fig. 4 Slump flow of AA slag-fly ash composites with steel fiber addition

also tested, and those values are all in between of the samples with $1 \%$ pure long and short fibers (20.6 and $23.1 \mathrm{~cm}$ ), following the tendency that a higher long/ short fiber ratio exhibits a relatively low slump flow. It should be noticed that one previous study mentioned that there is an optimum long/short fiber ratio in terms of workability in Portland cement based system [48], while this phenomenon is not observed in this study. It may imply that the slump flow in hybrid fiber conditions may also be influenced by other factors such as total fiber content, binder types, water dosage and utilization of superplasticizers.

\subsection{Compressive strength}

The 7 and 28 days compressive strengths of mixtures with different long and short fiber contents are depicted in Fig. 5. Generally, there is a significant increase in strength when the steel fiber is incorporated; and mixtures with long steel fiber exhibit slightly higher compressive strength than the ones with short fibers. For the reference sample, the compressive strength is $65.4 \mathrm{MPa}$ at 7 days, and it increases to $81.1 \mathrm{MPa}$ after 28 days of curing. When short fibers up to $1 \%$ are added, the compressive strength increases to 73.35 and $89.9 \mathrm{MPa}$ at 7 and 28 days, respectively. It indicates that although the steel

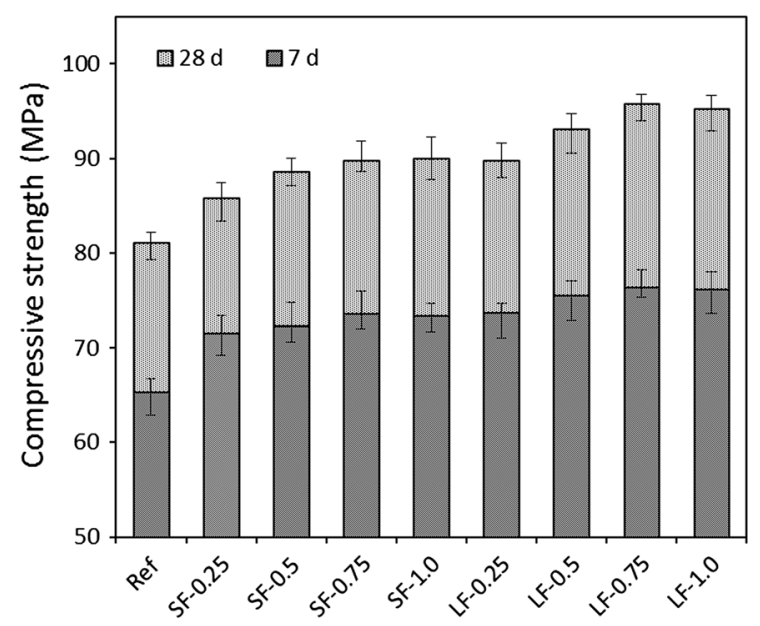

Fig. 57 and 28 days compressive strength of AA slag-fly ash composites with long or short fiber addition 
fiber is well known for improving the tensile or flexural strength, it can also bridge the cracks and retard their propagation to some extent during the compression loads. It should be noted that the mixes with 0.75 and $1 \%$ fiber content do not show significant difference in strength, which reveals that there is a limitation in contributing the compressive strength by steel fibers. The limited increase or even decrease in strength because of the fiber addition is also reported in the previous studies [31, 34, 49], it is suggested that this phenomenon is due to the combined effect of fiber addition and porosity. The optimum fiber content in terms of compressive strength may vary from different cases, and for a certain application, the relation between fiber dosage and compressive strength should be taken into consideration during the mix design process.

Similar to the effect of short fibers, the incorporation of long fibers leads to a relatively sharp increase with a dosage of $0.25 \%$, followed by a continuous but slight increase of strength up to around $1 \%$. Also no significant difference in compressive strength is shown in mixes with 0.75 and $1 \%$ long fiber content. The replacement of short and long fibers by $1 \%$ results in a strength increment of 11 and $17.5 \%$, respectively; showing an ideal fiber efficiency. It is important to notice that mixes with long fibers present higher strengths than the short fiber in general, which is due to the higher efficiency of long steel fibers in inhibiting the growth of macro-cracks.

A total fiber content of $1 \%$ is chosen for investigating the effect of hybrid steel fibers. Mixtures with four different long/short fiber ratios (80/20, 60/40, 40/60 and $20 / 80$ by volume) are applied and the 7 and 28 days compressive strengths are presented in Fig. 6. With a fixed total amount of fiber dosage, the compressive strength firstly increases when lowering the long/short fiber ratio, reaching the maximum strength in mixes with long/ short ratio of $60 / 40$, followed by a gradual decrease. This result indicates the beneficial effect of using hybrid steel fiber on compressive strength, by doing so a higher strength can be achieved with the same fiber content, and a certain fraction of long/short fibers may exhibit the optimum performance. Additionally, the relatively high strength of all mixes in general is also due to the utilization of particle packing methodology.

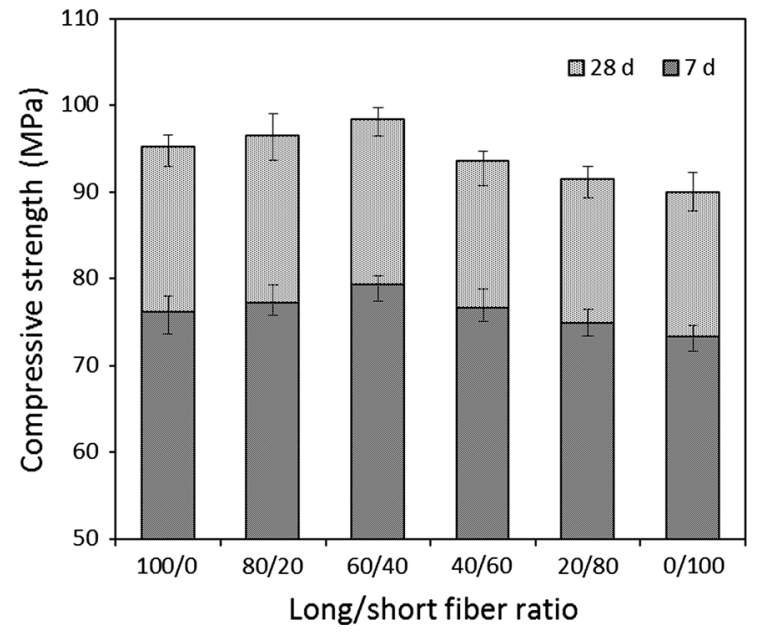

Fig. 67 and 28 days compressive strength of AA slag-fly ash composites with hybrid fiber addition

\subsection{Stress-strain behavior}

3-point bending test is performed to obtain the stressstrain relation (see Fig. 2). The strain is calculated by the determined displacement that is measured by a displacement transducer. The applied load is automatically recorded in a computer. The stress-strain relation is collected by the default program in the instrument, which is then exported for analysis. The 28 days stress-strain curves of mixtures with short, long and hybrid steel fibers are shown in Figs. 7, 8 and 9, respectively. It can be seen from Fig. 7 that the addition of only short steel fiber increases the ultimate

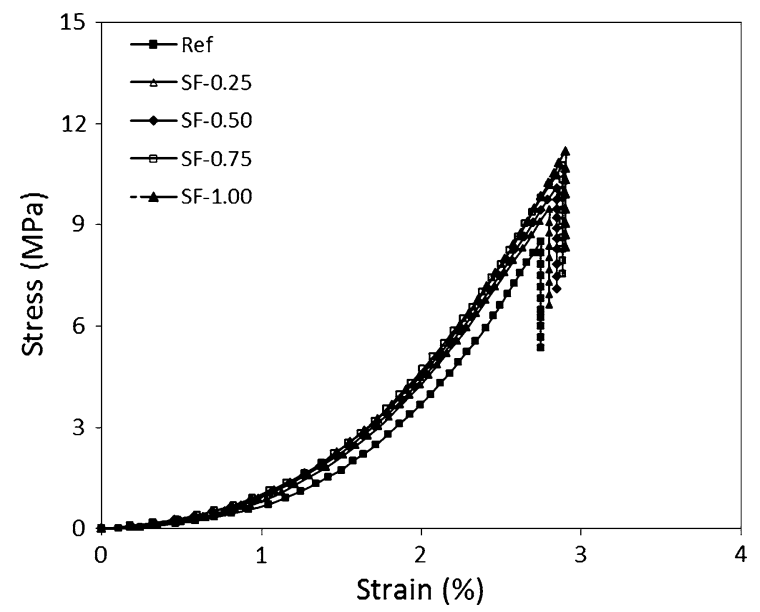

Fig. 7 Stress-strain curve of AA slag-fly ash composites with short fiber addition 


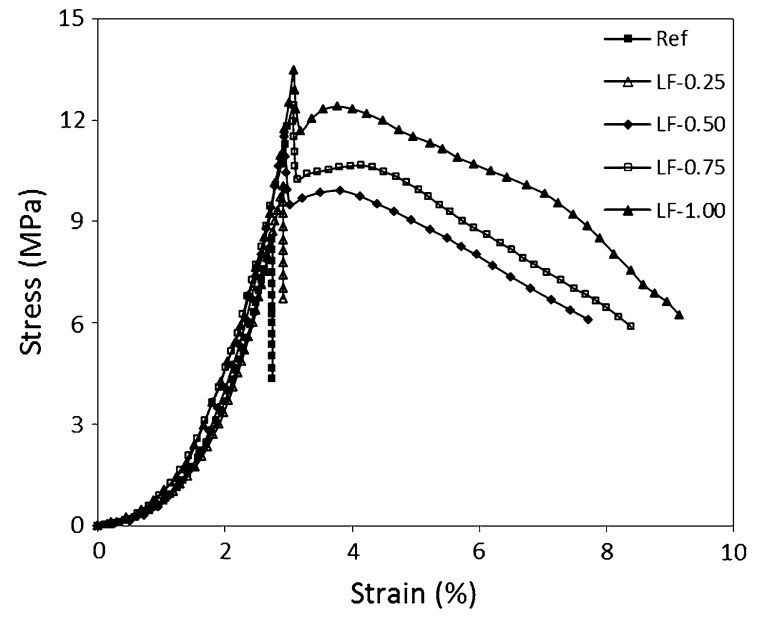

Fig. 8 Stress-strain curve of AA slag-fly ash composites with long fiber addition

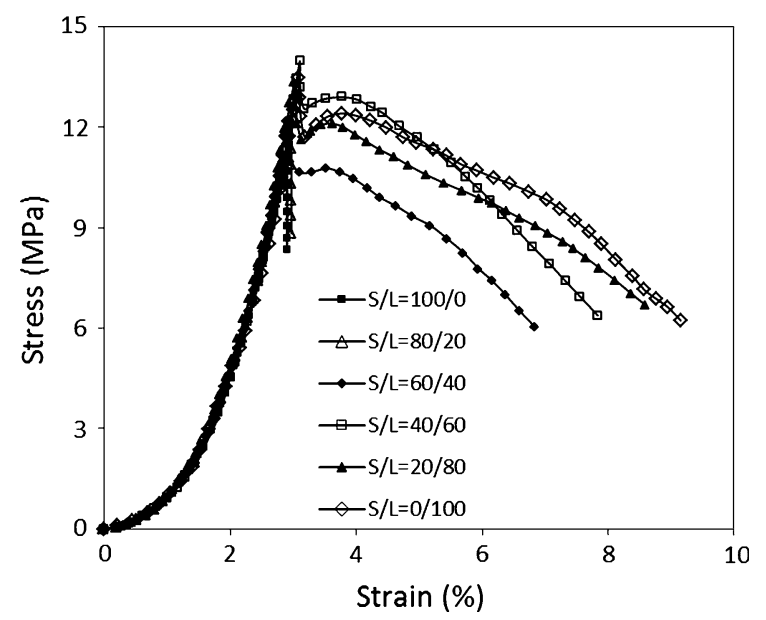

Fig. 9 Stress-strain curve of AA slag-fly ash composites with hybrid fiber addition

flexural strength. The flexural strength for samples without fiber incorporation is $8.5 \mathrm{MPa}$, which gradually increases to $11.2 \mathrm{MPa}$ when increasing the short fiber content up to $1 \%$, showing a relative strength increase of $31.8 \%$. A slight but detectable increase in strain is also observed. However, the fracture mode of the mixtures with short fibers remains the same as the reference sample: the brittle fracture. Moreover, the addition of only short fibers exhibits very limited influence on the energy absorption capacity.

The influence of short fiber on the stress-strain behaviors is attributed to shape of this fiber, the relatively short length and diameter makes this fiber capable of inhibiting the micro cracks under flexural loads, thus the flexural strength is increased as a result (for instance, with a $1 \%$ fiber addition a relative strength increase of $31.8 \%$ is resulted). However, as the loading continues to increase, the micro cracks develop and merge into larger ones and short fiber becomes less effective in macro crack bridging due to its limited length, therefore the failure mode remains the same as plain concrete, i.e. brittle fracture.

Figure 8 depicts the stress-strain curves of samples with long fiber addition. Compared to the effect of short fibers, a more significant improvement in ultimate flexural strength and plastic fracture is presented. For instance, when only $0.25 \%$ (by volume) long fiber is incorporated, the flexural strength increases from 8.5 MPa to 10.0 MPa, showing a more obvious increase (17.6\% improvement) compared to the ones with the same amount of short fiber. It indicates that long fibers are more effective in improving the flexural strength. This is attributed to the longer size of long fibers which makes them more oriented between two imaginary borders, thus a better capacity of preventing the growth of macro cracks can be achieved. The sudden stress loss after the peak load is caused by the occurrence of initial failure crack, and the following stress increase is due to the bonding force between the steel fiber and the matrix, then the stress starts to decrease again until the fiber cannot hold the imposed force anymore. It should be noted that the addition of short and long fibers by $1 \%$ increases the flexural strength by 31.3 and $58.5 \%$, respectively; showing much higher increments than the compressive strength.

The influence of hybrid steel fiber on flexural strength is presented in Fig. 9. The fiber content for all mixes is fixed at $1 \%$ and samples with only long or short fibers are used as references. For mixes with long fiber contents no lower than $40 \%$, plastic fracture is presented. As the long fiber friction increases, mixes show generally a higher energy absorption capacity and a lower stress drop rate after reaching the stress peak; which shows again the higher efficiency of long fibers in bridging the macro-cracks and therefore a more stable post-peak response. However, although mixes show an increased energy absorption capacity with the increasing long fiber content, samples with 60-100\% long fiber present a comparable post-peak response in general, and the highest flexural strength is shown in mixes with a short/long fiber ratio of 40/60. It confirms that the ultimate flexural strength is not well 
linked to the toughness. Besides, it can be noticed that the initial elastic period is not linear, which is caused by the limitations of the used testing machine, namely a certain period before stable loading is still needed after the initial load and clamp, and meanwhile the stress-strain curve is already collected. Nevertheless, since all the mixtures share a constant testing procedure, it is scientifically reliable to evaluate the effect fiber addition by investigating the shifts in stressstrain curves; and reasonable comparisons within the tested samples can still be made.

It is well known that the main contribution of steel fibers in reinforcing the mechanical properties is their ability to bridge the cracks and to retard their propagation; and short fibers are efficient in bridging the micro-cracks while long fibers are more effective in inhibiting the macro-cracks. According to [32, 33], the positive effect of hybrid fiber on mechanical properties is assigned to the different mechanisms of short and long fibers in restricting the cracks: (1) The short steel fiber can bridge the micro cracks in a more efficient manner, because with the same fiber addition volume, short fibers will have higher number due to their smaller individual volume. While as the micro cracks merge into larger ones with higher crack widths, short fibers may become less active due to their limited length. (2) Long fibers are more oriented between two imaginary borders, which are more efficient in preventing the macro cracks by nature. Besides, they can also form a barrier for short fibers and confine their rotation, thus the short fiber can be better oriented together with long fiber. Therefore, the hybrid usage of long and short fibers inhibit the cracking process from both micro and macro levels, and the synergetic effect of these two facts results in a higher resistance to the loading. The results also show that the fibers work in a similar role in alkali activated binder systems as in Portland cement system.

\subsection{Water permeable porosity}

The influences of fiber length and hybrid steel fibers on 28 days water permeable porosity are shown in Fig. 10. All mixtures show similar levels of porosity in overall, and the fiber addition shows limited but detectable influence on the porosity. For samples without fiber addition, the porosity is $17.2 \%$ at 28 days; when short fiber is added up to $1 \%$, the porosity increases almost linearly to $17.8 \%$. Similarly,

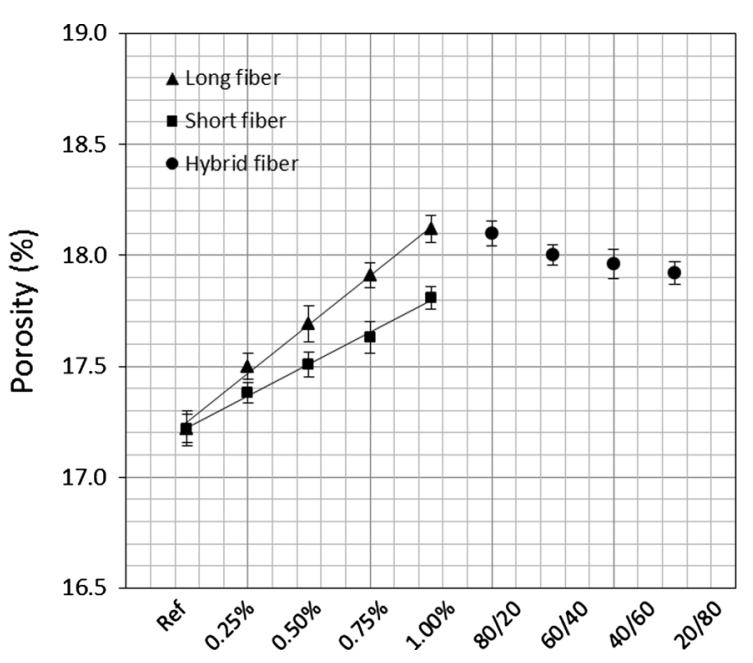

Fig. 10 Effect of fiber length and hybrid fiber on 28 days porosity

the incorporation of long fibers also leads to a slight increase of porosity up to $18.1 \%$. The increment of porosity due to the fiber addition is in constant with the previous study on cement based system [41], showing that the effect is independent of the binder type. It is suggested that the increased porosity due to the fiber addition is attributed to the internal forces between the fibers and aggregates, and/or the fibers themselves, which change the structure of the granular skeleton and reduce the packing density [32]. With the same fiber dosage, the long steel fiber exhibits a more significant influence on porosity than the short ones; indicating that longer fibers may present a more obvious effect on changing the granular skeleton, while the short ones can be relatively better dispersed within the matrix thanks to their smaller length and diameter. The two straight trend lines shown in Fig. 10 clarify that when the fiber content is increased in the matrix, there is a linear increment of the porosity in general, although slight deviations are observed. Different slopes of these two lines refer to their different affecting efficiency on the porosity.

Concerning the effect of hybrid fibers, as shown in Fig. 10, that the relation between the porosity and fiber composition seems to follow a similar tendency as the effect of single fibers, and samples with a higher fraction of long fibers exhibit a higher porosity. It seems that the porosity of the hybrid mixes is only a physical combination of the ones with single fibers, and the hybrid usage of these two fibers does not show any synergetic effect on porosity. It can be seen that 
both compressive and flexural strength increase with the increasing fiber content in general, but the porosity also increases at the same time. It is suggested that the final mechanical property is the apparent result of the combined effect of steel fiber and porosity. On the one hand, the addition of steel fiber can efficiently inhibit the generating and growing of cracks, especially when hybrid fiber is applied, thus the mechanical properties are improved in general; while on the other hand, the increased porosity due to the fiber addition may lead to the strength reduction. It is obvious that within the applied fiber dosage in this study, the crack-bridging behavior due to the fiber addition seems to present a stronger effect than the porosity increment, and then the mechanical properties exhibit an increase in general. It should also be noticed that beyond the fiber dosage of $1 \%$, the increment of compressive strength is no longer significant; it could be an indication that the increased porosity may show a more obvious effect over the crack-bridging effect at higher fiber contents. It is believed that the relatively poor flowability of the long fiber mixes is also a reason for the higher porosity.

\subsection{Drying shrinkage}

Figure 11 depicts the drying shrinkage results of mixes with only long or short steel fibers until 28 days and each value is an average of two measurements. It is apparent that the reference sample exhibits an obvious length change over time, especially during the first few days. It is commonly known that the drying

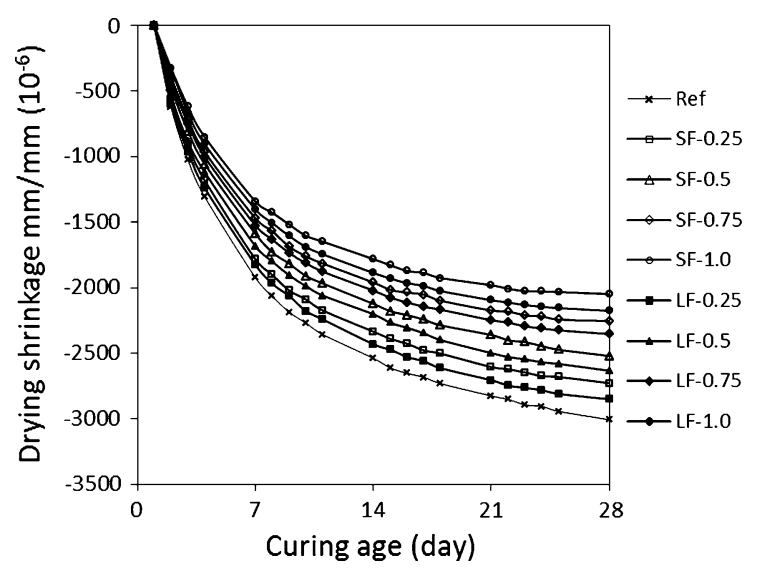

Fig. 11 Drying shrinkage of AA slag-fly ash mortars with different fiber lengths shrinkage is caused by the evaporation of free water from the pores of the hardened matrix [54], and a generally higher drying shrinkage is usually shown in alkali activated materials compared to the Portland cement based materials. As shown in Fig. 11, the shrinkage decreases with the increasing steel fiber content up to $1 \%$. It reveals that the fiber addition can be used as an efficient approach of inhibiting the drying shrinkage of alkali activated materials in this case. Besides, a relatively high drying shrinkage of the reference sample was observed in the previous research of the author $\left(-3996 \times 10^{-6}, 28\right.$ days of curing [50]), where the same starting materials' composition but different batches of slag were used; it is suggested that the difference in shrinkage is due to the different applied raw materials, the nature of the starting material (such as chemical composition and fineness) may also have a significant effect on the shrinkage behavior. It can be observed from Fig. 11 that for a fixed fiber dosage, mixes with long fiber present relatively high values compared to the ones with short fiber, indicating that the long fiber is slightly less effective than short fiber in inhibiting the shrinkage; but a long fiber addition of $1 \%$ still exhibits a shrinkage reduction rate of $27.6 \%$ compared to the reference sample.

The present results are in agreement with the general conclusions from the previous investigations that the steel fiber addition can effectively reduce the drying shrinkage [51, 52]; however, drying shrinkage that is independent of the fiber length was also reported [31]. It reveals that the origin of the starting materials (both the applied binders and steel fibers), sample shape and testing conditions may also show an influence on the final results. Considering the fiber addition slightly increases the porosity, it is more likely that the significantly reduced drying shrinkage is assigned to the efficiency of steel fibers in maintaining the volume stability of the matrix. The evaporation of free water from the matrix can result in a reduction on the absolute volume, and meanwhile tensile stresses may arise from the resulted internal restraints [53]. When steel fiber is incorporated, the generated tensile stresses will be imposed on the fiber (on the matrix as well), due to the high elastic modulus and bridging effect of steel fiber, the influence of this inner force on shrinkage can be suppressed to some extent. Concerning the effect of hybrid fiber, the tested mixes are having the constant total fiber content 
(1 vol\%) with different long/short fiber ratios $(0 / 100$, $20 / 80,40 / 60,60 / 40,80 / 20$ and 100/0 wt $\%$ ). The results show that samples with higher short/long fiber ratios exhibit a slightly lower shrinkage, while all mixtures present a similar level of drying shrinkage in general; which indicates that the fiber content possesses a more significant influence than the fiber type, and the utilization of hybrid fiber seems not to show obvious synergetic effect regarding shrinkage. Concerning the effect of hybrid fiber is limited; their relations with shrinkage are not shown in the form of figure in this study, as presented above.

\subsection{Other remarks}

The gel structure of this alkali activated binder is identified by using Fourier transform infrared spectroscopy and thermo-gravimetric analyses. The infrared spectra of the unreacted slag and fly ash, as well as the reaction products after 1,7 and 28 days of curing are given in Fig. 12. For the starting materials, a main vibration band at around $900 \mathrm{~cm}^{-1}$ and a small shoulder at around $670 \mathrm{~cm}^{-1}$ are shown in the original slag, which is assigned to the asymmetric stretching vibration of terminal $\mathrm{Si}-\mathrm{O}$ bonds [54] and the stretching vibration of tetrahedral T-O groups [55], respectively. As for the fly ash, a main absorption band that is shown at around $1020 \mathrm{~cm}^{-1}$, and several weak absorption bands at around 1080, and $600-800 \mathrm{~cm}^{-1}$,

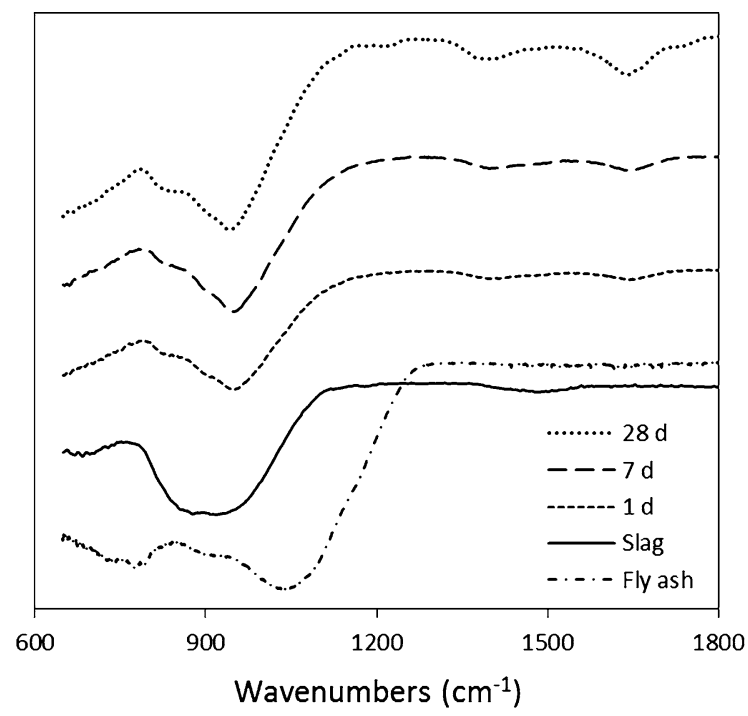

Fig. 12 FTIR spectra of the starting materials and AA slag-fly ash blends at 1,7 and 28 days indicating the presence of large amount of the bridge $\mathrm{Si}-\mathrm{O}-\mathrm{T}$ bonds [56] and small amount of quartz and mullite [57], respectively. After activation, the main absorption band shifts to around $940 \mathrm{~cm}^{-1}$ that is assigned to the asymmetric stretching vibration of the non-bridging $\mathrm{Si}-\mathrm{O}$ bonds [58], showing that the main reaction products exhibit a chain structure. They are generally regarded as C-A-S-H type gels, which have similar structure as the hydration products of Portland cement, but with higher alumina contents and lower $\mathrm{Ca} / \mathrm{Si}$ ratio, also no intrinsic difference is observed based on X-ray pair distribution function analysis [59]. The slight shoulder at around $815 \mathrm{~cm}^{-1}$ together with the absorption band at $1400 \mathrm{~cm}^{-1}$ reveal the presence of carbonates [60], and the absorption bands at $1640 \mathrm{~cm}^{-1}$ and around $3200 \mathrm{~cm}^{-1}$ (not shown in the figure) are assigned to the vibration of bound water [61]. No significant structural changes are observed between the curing age of 1, 7 and 28 days.

The thermogravimetric results of paste sample at the age of 1, 7 and 28 days are depicted in Fig. 13. It can be seen that there is a significant mass loss before around $105{ }^{\circ} \mathrm{C}$ due to the loss of physically bound water [62]. A gradual decrease in mass until $600{ }^{\circ} \mathrm{C}$ is shown followed by a stable curve with remarkably low mass loss till $1000{ }^{\circ} \mathrm{C}$. There is no abrupt decrease in mass loss between the temperature range of around 105 and $1000{ }^{\circ} \mathrm{C}$, which indicates that mass loss within this temperature range is mainly due to gradual decomposition of C-A-S-H type gels. The total mass

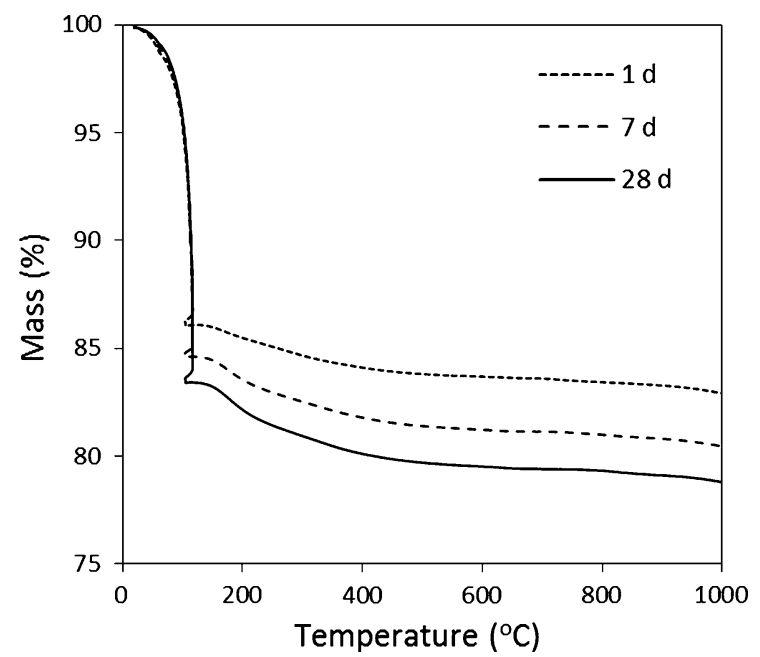

Fig. 13 TG analyses of AA slag-fly ash blends at 1, 7 and 28 days 
loss between around 105 and $1000{ }^{\circ} \mathrm{C}$ shows a small increment from 3.8 to $4.9 \%$ between 1 and 28 days. The relatively small increase in bound water content with age may suggest again the completion of the main reaction process within the first day of curing.

Besides, the fiber content used in this case is limited to $1 \%$ by volume, which aims at investigating the effect of fiber length the use of hybrid fiber on those discussed properties, without significantly increasing the total costs of the developed materials. Nevertheless, it is also interesting to investigate the mixes with higher fiber contents in the future studies, since higher fiber dosages are commonly used in the case of high performance cement based composites and then comparisons between different binder systems can be made with convenience. The increased total fiber content may show different effects on different issues, the flowability may continuously decrease and the porosity keeps increasing, since the fiber addition only presents physical effect. To what extent can the steel fiber inhibit the drying shrinkage is another issue that deserves further investigations. Besides, for the applied particle packing methodology, it can be seen from Fig. 1 that the optimized mix still exhibits a lower amount of fine particles within the range between 0.3 and $20 \mu \mathrm{m}$ compared to the target curve. This is due to the limited amount of fine particles of the provided materials. Thus if additional fine materials can be used in the future studies, a better packing can be achieved, and thus the porosity and other related performances can be further improved. In overall, by using the hybrid steel fiber, a certain combination of the discussed properties can be achieved; also the advantages of both long and short fibers can be taken, especially in improving the stress stain behaviors and reducing the shrinkage, which brings this type of alternative binders a brighter future in high performance applications.

\section{Conclusions}

This paper investigates the performances of alkali activated slag-fly ash composites that are reinforced by long and/or short steel fibers, and the mortar samples are designed by applying the modified Andreasen and Andersen particle packing model. Based on the experimental results, the following conclusions can be drawn:
- The addition of long and short fibers (up to $1 \%$ by volume) decreases the slump flow from 25.9 to 20.6 and $23.1 \mathrm{~cm}$, respectively. The utilization of long steel fiber presents a more significant effect because of the higher influence on the cohesive forces within the matrix. Nevertheless, the designed mixes show in overall relatively good workability.

- The compressive strength is increased by $10.3 \% /$ $16.8 \%$ when short/long steel fiber is incorporated, respectively. The fiber content of around $1 \%$ by volume reaches the limit of strength improvement. The hybrid usage of long and short fibers presents a synergetic effect by inhibiting the cracks from both micro and macro levels, resulting in the presence of an optimum strength.

- The addition of long fiber with contents higher than $0.25 \%$ by volume changes the fracture mode from brittle into plastic, and the flexural strength and toughness are also remarkably increased by the long fiber incorporation. The addition of short fiber increases the flexural strength in a relatively small level without changing the fracture mode. Synergetic effect of long and short fibers is also shown in flexural behaviors.

- The main reaction product of this blended alkali binder is a chain structured C-A-S-H type gels, with the chemically bound water content of around $5 \%$ at 28 days; and without other obvious crystalline phases. The gel structure remains stable after 1 day of curing, indicating the completion of the main reaction process at early age of curing.

- The addition of long and short fibers up to $1 \%$ leads to the water permeable porosity increment of 0.6 and $0.9 \%$ respectively, attributed to the change of the granular skeleton. The deployment of hybrid fibers leads to a slightly reduced porosity.

- Due to the ability of effectively suppressing the generated inner forces, the utilization of long and short steel fiber significantly reduces the 28 days drying shrinkage up to 27.6 and $31.9 \%$, respectively. The hybrid usage of long and short fibers exhibits more a physical combination rather than synergetic effect.

Acknowledgements This research was supported by China Scholarship Council and the Department of the Built Environment at Eindhoven University of Technology. The authors gratefully thank Mr. P. de Vries (ENCI B.V., the 
Netherlands) for the materials supply. Furthermore, the authors wish to express their gratitude to the following sponsors of the Building Materials research group at TU Eindhoven: Rijkswaterstaat Grote Projecten en Onderhoud; GranietImport Benelux; Kijlstra Betonmortel; Struyk Verwo; Attero; Enci; Rijkswaterstaat Zee en Delta-District Noord; Van Gansewinkel Minerals; BTE; V.d. Bosch Beton; Selor; GMB; Geochem Research; Icopal; BN International; Eltomation; Knauf Gips; Hess AAC Systems; Kronos; Joma; CRH Europe Sustainable Concrete Centre; Cement \& Beton Centrum; Heros and Inashco (in chronological order of joining).

\section{Compliance with ethical standards}

Conflict of interest The authors declare that they have no conflict of interest.

Open Access This article is distributed under the terms of the Creative Commons Attribution 4.0 International License (http:// creativecommons.org/licenses/by/4.0/), which permits unrestricted use, distribution, and reproduction in any medium, provided you give appropriate credit to the original author(s) and the source, provide a link to the Creative Commons license, and indicate if changes were made.

\section{References}

1. Wang SD, Scrivener KL, Pratt PL (1994) Factors affecting the strength of alkali-activated slag. Cem Concr Res 24(6): 1033-1043

2. Fernández-Jiménez A, García-Lodeiro I, Palomo A (2007) Durable characteristics of alkali activated fly ashes. J Mater Sci 42:3055-3065

3. Bakharev T, Sanjayan JG, Cheng YB (2003) Resistance of alkali-activated slag concrete to acid attack. Cem Concr Res 33:1607-1611

4. Hai YZ, Kodur V, Shu LQ, Liang C, Bo W (2014) Development of metakaolin-fly ash based geopolymers for fire resistance applications. Constr Build Mater 55:38-45

5. Puertas F, Fernández-Jiménez A (2003) Mineralogical and microstructural characterisation of alkali-activated fly ash/ slag pastes. Cem Concr Compos 25:287-292

6. Brough AR, Atkinson A (2002) Sodium silicate-based alkali-activated slag mortars: part I. Strength, hydration and microstructure. Cem Concr Res 32:865-879

7. Li C, Sun HH, Li LT (2010) A review: the comparison between alkali-activated slag $(\mathrm{Si}+\mathrm{Ca})$ and metakaolin (Si + Al) cements. Cem Concr Res 40:1341-1349

8. Lee NK, Lee HK (2013) Setting and mechanical properties of alkali-activated fly ash/slag concrete manufactured at room temperature. Constr Build Mater 47:1201-1209

9. Rashad AM (2013) Properties of alkali-activated fly ash concrete blended with slag. Iran J Mater Sci Eng 10(1):57-64

10. Aydin S (2013) A ternary optimization of mineral additives of alkali activated cement mortars. Constr Build Mater 43:131-138

11. Sugama T, Brothers LE, Van de Putte TR (2005) Acidresistant cements for geothermal wells: sodium silicate activated slag/fly ash blends. Adv Cem Res 17(2):65-75
12. García-Lodeiro I, Macphee DE, Palomo A, FernándezJiménez A (2010) Effect on fresh C-S-H gels the simultaneous addition of alkali and aluminium. Cem Concr Res 40:27-32

13. Ismail I, Bernal SA, Provis JL, Nicolas RS, Hamdan S, Deventer JSJ (2014) Modification of phase evolution in alkali-activated blast furnace slag by the incorporation of fly ash. Cem Concr Compos 45:125-135

14. Yip CK, Lukey GC, van Deventer JSJ (2005) The coexistence of geopolymeric gel and calcium silicate hydrate at the early stage of alkaline activation. Cem Concr Res 35:1688-1697

15. Chi M, Huang R (2013) Binding mechanism and properties of alkali-activated fly ash/slag mortars. Constr Build Mater 40:291-298

16. Puertas F, Martínez-Ramírez S, Alonso S, Vázquez E (2000) Alkali-activated fly ash/slag cement. Strength behaviour and hydration products. Cem Concr Res 30:1625-1632

17. Bernal SA, Provis JL, Rose V, Mejía de Gutierrez A (2011) Evolution of binder structure in sodium silicate-activated slag-metakaolin blends. Cem Concr Compos 33:46-54

18. Bernal SA, Mejía de Gutierrez A, Provis JL (2012) Engineering and durability properties of concretes based on alkali-activated granulated blast furnace slag/metakaolin blends. Constr Build Mater 33:99-108

19. Gao X, Yu QL, Brouwers HJH (2015) Reaction kinetics, gel character and strength of ambient temperature cured alkali activated slag-fly ash blends. Constr Build Mater 80:105-115

20. Gao X, Yu QL, Brouwers HJH (2015) Properties of alkali activated slag-fly ash blends with limestone addition. Cem Concr Compos 59:119-128

21. Gao X, Yu QL, Brouwers HJH (2015) Characterization of alkali activated slag-fly ash blends containing nano-silica. Constr Build Mater 98:397-406

22. Shi C, Krivenko PV, Roy DM (2006) Alkali-activated cements and concretes. Taylor \& Francis, Abingdon

23. Małolepszy J (1989) The hydration and the properties of alkali activated slag cementitious materials. Ceramika 53:7-125

24. Palomo A, Fernández-Jiménez A, López-Hombrados C, Lleyda JL (2007) Railway sleepers made of alkali activated fly ash concrete. Rev Ing Constr 22(2):75-80

25. Sahmaran M, Yaman IO (2007) Hybrid fiber reinforced selfcompacting concrete with a high-volume coarse fly ash. Constr Build Mater 21:150-156

26. Bencardino F, Rizzuti L, Spadea G, Swamy RN (2010) Experimental evaluation of fiber reinforced concrete fracture properties. Compos Part B Eng 41:17-24

27. Bernal S, Gutierrez RD, Delvasto S, Rodriguez E (2010) Performance of an alkaliactivated slag concrete reinforced with steel fibers. Constr Build Mater 24:208-214

28. Corinaldesi V, Moriconi G (2004) Durable fiber reinforced self-compacting concrete. Cem Concr Res 34:249-254

29. Yazici S, Inan G, Tabak V (2007) Effect of aspect ratio and volume fraction of steel fiber on the mechanical properties of SFRC. Constr Build Mater 21:1250-1253

30. Bentur A (1989) Fiber-reinforced cementitious materials. In: Skalny JP (ed) Material science concrete. The American Ceramic Society, Westerville 
31. Aydin S, Baradan B (2013) The effect of fiber properties on high performance alkali-activated slag/silica fume mortars. Compos Part B Eng 45:63-69

32. Grunewald S (2004) Performance-based design of selfcompacting fibre reinforced concrete. Delft University of Technology, Delft

33. Markovic I (2006) High-performance hybrid-fibre concrete development and utilization. Delft University of Technology, Delft

34. Rashad AM (2013) A comprehensive overview about the influence of different additives on the properties of alkaliactivated slag - a guide for Civil Engineer. Constr Build Mater 47:29-55

35. Bernal S, Gutierrez RD, Rodriguez E, Delvasto S, Puertas F (2009) Mechanical behavior of steel fiber-reinforced alkaliactivated slag concrete. Mater Constr 29:53-62

36. Andreasen AHM, Andersen J (1930) Über die Beziehungen zwischen Kornabstufungen und Zwischenraum in Produkten aus losen Körnern (mit einigen Experimenten). Kolloid Z 50:217-228 (in German)

37. Funk JE, Dinger DR (1994) Predictive process control of crowded particulate suspensions, applied to ceramic manufacturing. Kluwer Academic Publishers, Boston

38. Hüsken G, Brouwers HJH (2008) Earth-moist concrete: application of a new mix design concept. Cem Concr Res 38:1246-1259

39. Brouwers HJH, Radix HJ (2005) Self-compacting concrete: theoretical and experimental study. Cem Concr Res 35:2116-2136

40. Brouwers HJH (2006) Particle-size distribution and packing fraction of geometric random packings. Phys Rev E 74(031309): 1-14

41. Yu QL, Brouwers HJH (2012) Development of a selfcompacting gypsum-based lightweight composite. Cem Concr Compos 34:1033-1043

42. Hunger M, Entrop AG, Mandilaras I, Brouwers HJH, Founti M (2009) The behavior of a microencapsulated phase change material in concrete. Cem Concr Compos 31:731-743

43. Hüsken G, Brouwers HJH (2008) A new mix design concept for earth-moist concrete: a theoretical and experimental study. Cem Concr Res 38:1246-1259

44. British standard EN 1015-3:1999. Methods of test for mortar for masonry Part 3: Determination of consistence of fresh mortar

45. British standard EN 196-1:2005. Methods of testing cement Part 1: Determination of strength

46. NT Build 492. Concrete, mortar and cement-based repair materials: chloride migration coefficient from non-steadystate migration experiments

47. Yu R, Spiesz P, Brouwers HJH (2014) Mix design and properties assessment of ultra-high performance fibre reinforced concrete (UHPFRC). Cem Concr Res 56:29-39

48. Yu R, Spiesz P, Brouwers HJH (2014) Static properties and impact resistance of a green ultra-high performance hybrid fibre reinforced concrete (UHPHFRC): experiments and modeling. Constr Build Mater 68:158-171

49. Susan B, Ruby DG, Silvio D, Erich R (2006) Performance of geopolymeric concrete reinforced with steel fibers. In: 10th International inorganic-bonded fiber composites conference, IIBCC 2006, Sao Paulo-Brazil, Universidade de Sao Paulo and University of Idaho, Sao Paulo, October 15-18 2006. P. 156-67

50. Gao X, Yu QL, Brouwers HJH (2016) Assessing the porosity and shrinkage of alkali activated slag-fly ash composites designed applying a packing model. Constr Build Mater 119:175-184

51. Choi SJ, Hong BT, Lee SJ, Won JP (2014) Shrinkage and corrosion resistance of amorphous metallic-fiber-reinforced cement composites. Compos Struct 107:537-543

52. Cao ML, Zhang C, Lv HF (2014) Mechanical response and shrinkage performance of cementitious composites with a new fiber hybridization. Constr Build Mater 57:45-52

53. Mindess S, Francis Young J, Darwin D (2003) Concrete, 2nd edn. Prentice Hall, Englewood Cliffs

54. Zhang ZH, Wang H, Provis JL, Bullen F, Reid A, Zhu YC (2012) Quantitative kinetic and structural analysis of geopolymers. Part 1. The activation of metakaolin with sodium hydroxide. Therm Acta 539:23-33

55. Kovalchuk G, Fernandez-Jimenez A, Palomo A (2007) Alkali-activated fly ash: effect of thermal curing conditions on mechanical and microstructural development-part II. Fuel 86:315-322

56. Hajimohammadi A, Provis JL, Deventer JSJ (2011) Timeresolved and spatially resolved infrared spectroscopic observation of seeded nucleation controlling geopolymer gel formation. J Colloid Interface Sci 357:384-392

57. Criado M, Fernandez-Jimenez A, Palomo A (2007) Alkali activation of fly ash: effect of the $\mathrm{SiO}_{2} / \mathrm{Na}_{2} \mathrm{O}$ ratio part I: FTIR study. Microporous Mesoporous Mater 106:180-191

58. Zhang ZH, Wang H, Provis JL, Bullen F, Reid A, Zhu YC (2012) Quantitative kinetic and structural analysis of geopolymers. Part 1. The activation of metakaolin with sodium hydroxide. Therm Acta 539:23-33

59. Claire EW, Luke LD, Monika H, Katharine P (2015) Intrinsic differences in atomic ordering of calcium (alumino) silicate hydrates in conventional and alkali-activated cements. Cem Concr Res 67:66-73

60. Bernal SA, Provis JL, Rose V, Mejía de Gutierrez A (2011) Evolution of binder structure in sodium silicate-activated slag-metakaolin blends. Cem Concr Compos 33:46-54

61. Yu P, Kirkpatrick RJ, Poe B, McMillan PF, Cong X (1999) Structure of calcium silicate hydrate (C-S-H): near-, mid-, and far-infrared spectroscopy. J Am Ceram Soc 82(3):742-748

62. Kong DLY, Sanjayan JG (2010) Effect of elevated temperatures on geopolymers paste, mortar and concrete. Cem Concr Res 40:334-339 